\title{
S2 ThelTLIS
}

\section{Towards an Indigenous Transdisciplinarity}

\author{
Anthony Cole, iPansophy Limited, 33 Philomel Crest, Welcome Bay, Tauranga 3112, Bay of Plenty, New Zealand. \\ Email: anthony@ipansophy.com
}

Received 2 December 2017; Revised 23 December 2017; Accepted 26 December 2017

Copyright (C) 2017 Anthony Cole. This is an open access article distributed under the Creative Commons Attribution License (https://creativecommons.org/licenses/by/4.0/), which permits unrestricted use, distribution, and reproduction in any medium, provided the original work is properly cited.

Available online 30 December, 2018 at www.atlas-journal.org, doi: 10.22545/2017/00091

\section{T}

his paper attempts to theoretically position and characterise an indigenous (Māori) transdisciplinarity in relation to (i) the transdisciplinary methodology of Basarab Nicolescu and (ii) mode-2 transdisciplinarity (i.e. the Zurich Model). This writing outcome is achieved by drawing attention to the existence of a 'cultural continuum' of knowledge development in which contemporary western science (entire) is viewed as one of an estimated 6,900 culturally mediated approaches to knowledge development that exist on planet Earth today. Recognition of the role of 'culture' and 'indigeneity' in knowledge development is shown to be essential, if we are to avoid the extinction of an estimated 50-90\% of the world's current linguistic (cf. cultural) diversity over the next 100 years. As a first step towards characterising an indigenous transdisciplinarity, this paper explores the knowledge development traditions of New Zealand Māori, as drawn from the experiences of the author and writings of pūkenga Māori (transl. Māori scholars).

Keywords: Indigenous transdisciplinarity, Transdisciplinary methodology, Cultural survival, Kaupapa Māori, Mode-2 transdisciplinarity.

\section{Introduction}

This paper draws on key characteristics of New Zealand Māori cultural identity and experiences in research to define what I describe in English as an indigenous (Māori) transdisciplinarity. The existence of an indigenous transdisciplinarity follows from the well-established fact that indigenous peoples have ways and means of knowledge development that differ from those employed in western science [1-3]. This difference has been highlighted by published literature on 'decolonising methodology' that is now contributed to by a growing number of indigenous scholars worldwide [4-7]. Much effort has been invested over the last 3 decades in developing the western scientific methodology and practice of transdisciplinarity [8-11]. By contrast, literature that compares and/or contrasts western scientific and indigenous perspectives on transdisciplinarity is difficult to find. This paper draws on my teaching, learning and involvement in Māori communities to create an initial step towards the theoretical and methodological characterisation of an indigenous (Māori) transdisciplinarity.

The contents of this paper are important because 
Māori and other indigenous cultures are a taonga tuku iho (transl. inherited treasure). While indigenous cultural survival is both feasible and desired, key survival (and wellbeing) indicators have been in decline for a long time [12]. Indigenous cultural survival and wellbeing are dependent on the continued use and adaptation of indigenous knowledge development traditions. Just how these knowledge traditions can find freedom of expression and co-exist with western science is a matter of grave concern given current and projected levels of cultural extinction. Furthermore, to achieve the goal of indigenous cultural survival, a number of pre-conditions are necessary. First, the free, daily expression of cultural language, values and institutions within functioning cultural ecosystems and landscapes. Second, the ability to adapt to change using creativity (incl. knowledge creation) and respond to disturbance events in ways that reclaim, reframe and reinstate essential cultural identity.

Cultural survival and wellbeing pre-conditions have proved very difficult to maintain during colonisation events. In New Zealand, the process of colonisation began in the mid 1840s and saw the rapid introduction and domination of a foreign language, religion, economy, approach to education and knowledge development [13]. Concerted pushback against these colonising influences was initiated in the mid 1970s with the revival of the Māori language. This was followed by efforts to decolonise state education in the 1980s and disciplinary science in the late 1990s [14-21].

Publication of the book 'Decolonising Methodologies' by Linda Tuhiwai Smith [22] represents an important milestone in the efforts of Māori communities and scholars to get recognition for the existence of a distinctive Māori cultural approach to knowledge development. Additional impetus was given to the work of decolonising 'education' with the writings of Brazillian born, Paulo Freire, whose book 'Pedagogy of the Oppressed' [23] and thinking on educational reform was eagerly embraced by Māori communities, academics and activists [24-26]. This decolonising watershed of the 1970-90s provided Māori communities, activists and scholars with the knowledge and tools needed to begin reclaiming their ancestral knowledge and reframing it in a modern-day Māori cultural approach to knowledge development (i.e. 'kaupapa Māori ${ }^{1}$ research'). While literature that

\footnotetext{
${ }^{1}$ Transl. 'knowledge creation grounded in Māori cultural
}

focuses on the decolonisation of disciplinary science is well-established, the relationship between kaupapa Māori research, indigenous knowledge development and transdisciplinarity is only just beginning to be explored [27-29]. This paper proposes an initial outline of this important theoretical landscape.

This 'theoretical' gap in contemporary indigenous knowledge development needs attention for a number of reasons. First, in academic terms, the holistic character of inidgenous knowledge development is difficult to justify and financially resource, when its legitimacy and relevance is constantly measured against an existing western scientific preoccupation with disciplinary specialisation. Second, as shown in this paper, while not identical, there are similarities between the creation of mātauranga Māori (transl. Māori knowledge) and the transdisciplinary methodology of Basarab Nicolescu (2005). Furthermore, the written scholarship of Basarab Nicolescu provides a thoughtful, well referenced and articulate critique of the limitations of classical western scientific methodology. This critique is of central importance to decolonising discourse. Third, transdisciplinarity is part of the emerging frontier of western science that aims to provide a more holistic approach to joint-problem-solving and collective knowledge development. An opportunity now exists for Māori and other indigenous scholars to understand and influence the methodological development, real-world and experimental applications of transdisciplinarity so that it does not become yet another colonising influence on indigenous peoples [30]. At present, this is a very real concern given that decolonising discourse appears to be largely missings from current transdisciplinary literature.

\subsection{Linguistic limitations}

The first challenge in any attempt to characterise what might be referred to in English as an 'indigenous transdisciplinarity' concerns our use of language in attempting to communicate 'meaning' across cultural boundaries. According to Nicolescu [9], the name 'transdisciplinary' comes from the language of western science and is believed to have been introduced by Jean Piaget (1896-1980). Concerning the meaning of transdisciplinary, Nicolescu [9] explains that in its English rendering, the word 'transdisciplinary' refers to that which is across, between and

\footnotetext{
identity'
} 
beyond the disciplines. In this linguistic construction of transdisciplinarity, the pre-existence of (western) academic disciplines is a 'fixed' reference point for categorising different approaches to the coordination of knowledge development - across, between and beyond disciplines. While there is no linguistic analogue for the English word 'transdiscplinary' in Te Reo Māori (transl. the Māori language), this is not to say that the 'meaning' of transdisciplinary knowledge development was foreign to my tuppuna (transl. Māori ancestors). Thus a challenge in this area of written scholarship is to compare 'meaning' across cultures, rather than just 'vocab'. Use of the English term 'indigenous transdisciplinarity' has been adopted in this paper because it is a useful means of communication with western scholars, a reference point that can be used to compare and contrast the knowledge development experiences of indigenous peoples with those of their 'western' counterparts.

If we shift our attention away from 'vocabulary' towards 'meaning' it is possible to show that the antecedents of modern-day transdisciplinarity can be traced back (historically) into former inidgenous cultural contexts [29]. Thus, from an indigenous cultural perspective, the emergence of transdisciplinary methodology and practice in western science might, respectfully, be considered as a relatively recent innovation, when compared with indigenous knowledge traditions. A failure to recognise the many and varied contributions of indigenous peoples towards holistic knowledge development appears to exist, because western scholars are still coming to terms with the idea that knowledge development is 'culturally mediated' (ref. section 2).

The middle English word 'culture' is a loan word that is believed to have come from the German 'kultur' and the Latin 'cultura'. According to Newbigin [31], the English notion of 'culture' as a distinctive race of people really only entered into English vocabulary and consciousness during the 20th Century This relatively recent conception of differing races of people challenged earlier ecclesiastical notions of a universal 'family of God' and imperialist notions of 'human civilisation' [31]. From an anthropological perspective, culture can be characterised by the existence of unique (pre-analytic) worldview perceptions; assumptions and beliefs about reality that are encoded in language, of which there are a documented 6,900 in existence today [12, 32-35].

In seeking to translate indigenous languages into
English, the existence of direct linguistic analogues (i.e. similar vocab, grammar and written expression) that can be used to accurately transfer 'meaning' across the English/indigenous language divide is rare. Thus, an approach toward 'indigeneity' from the vocabulary and metaphysical foundations of western science is difficult at best. An aim in writing this paper is to try and show that the transdisciplinary methodology of Basarb Nicolescu [9] provides a helpful theoretical and axiomatic foundation, within western science, for dialogue and collaboration with Māori culture (and potentially other indigenous knowledge traditions). An additional pre-requisite for those wishing to build dialogue and collaborative activities with indigenous peoples is the adoption of indigenous language competency. Therefore, to assist readers, reference to Māori language in this paper is supported by in-text English translation [36, 37], even though this interpretive reading aid often fails to capture the full richness and nuances of a Māori worldview.

While clearly challenging, this language translation problem is also profoundly important for transdisciplinary endeavour because the existence of linguistic discontinuities provides evidence of fundamentally different pre-analytic worldview conceptions, assumptions and beliefs about the nature of reality. In particular, indigenous cultural conceptions of reality are characteristically holistic (cf. 'transdisciplinary') in nature [38, 39].

\subsection{Scope and Limitations of This Paper}

This paper draws on the writings of Māori scholars and my own experiences in teaching, learning and working with Māori communities to 'generalise' and theoretically position a Māori cultural approach to knowledge development [40-42] in relation to: (i) the transdisciplinary methodology of Basarab Nicolescu (i.e. the Nicolescuian Model) and (ii) mode-2 transdisciplinarity (i.e. the Zurich model), [10]. While generalisation is commonly used in western science as an aid to categorisation, its use in indigenous cultural contexts is problematic because it tends to over-simplify a social reality that is rich, diverse and complex. Thus, this written contribution is very much a first step towards understanding.

I offer this written contribution as a scholar from New Zealand of Māori descent. I was initially trained in the western science tradition, but in 2005 I began a personal journey in 'decolonising' much of 
what I was taught at university. One aim of this journey was to better understand how my tūpuna (transl. Māori ancestors) developed knowledge to support the survival and wellbeing of their whānau (transl. the Māori family ecosystem). The English word 'family' is limited in capturing the meaning of the Māori concept of 'whānau'. In Māori culture, the concept of whānau is holistic and inclusive. The whakapapa (transl. geneaology of 'whānau') describes an 'ecosystem' rather than a nuclear family. This Māori ecosystem is composed of Papatūannuku (transl. our Earth mother), Ranginui (our Sky father), Atua (transl. the children of Papatūānuku and Ranginui) who are the kaitiaki (transl. guardians, caretakers) of the different domains of the natural world and Tangata Whenua (transl. Māori commnuities) who are the teina (transl. younger siblings) of this 'ecological' Māori family. This 'whānau Māori' identity is profoundly important.

By today's standards, the survival of whānau Māori (transl. the Māori family ecosystem) on the New Zealand island archipalego for approximately 800-1,000 years, prior to the onset of British colonisation [13] was a remarkable achievement. This is especially because my tūpuna (transl. Māori ancestors) managed to maintain their physical survival along with the survival and wellbeing of the entire Māori family ecosystem. By comparison, these same goals are very difficult to achieve in a modern-day capitalist market economic context. Thus, understanding the knowledge development traditions of my tūpuna (transl. Māori ancestors) is an important contribution towards the future survival and wellbeing of our culture.

\section{The Cultural Mediation of Knowledge Development}

Before an attempt is made to compare and contrast western scientific and indigenous perspectives on transdisciplinarity, it is first necessary to explain in what way 'knowledge development' is culturally mediated. We live in a period of human history in which mode -1 disciplinarity (i.e. an adaptation of classicial western scientific methodology) has become dominant and mainstreamed. Western scientific thought is taught in state schools and plays a critical role in the innovation engine that drives modern economic growth. The dominance of western scientific thought, methodology and method is underpinned by decades of remarkable achievements that have had both positive and negative effects on human and ecological wellbeing. In summary, it seems fair to say that western science works well in its own cultural context, where it promotes the survival and wellbeing of its own (i) worldview assumptions (cf. axioms), (ii) ontology (e.g. English, mathematics), (iii) values (i.e. ethics, desired outcomes, codes of professional conduct) and (iv) epistemology (i.e. methodology, methods). Western science is an emerging "cultural entity'. When combined with its own disciplinary elaboration of market economics, western science has become a surrogate 'culture' for a large part of the world's population. The need for cultural surrogacy of this kind is a direct consequence of decline in preexisting cultural identities; leading to the extinction of the world's former cultural diversity.

While western science seems to work well in its own cultural contexts, its application in indigenous cultural contexts can result in unwanted outcomes that contribute to cultural decline and extinction. Western scientists have been slow to come to terms with this problem, the existence of which does not imply that western science is somehow wrong. However, it is unhelpful to view western science as superior in terms of its knowledge achievements or knowledge development methods. Western science does not provide a 'benchmark' for measuring the relative worth or value of non-western scientific knowledge traditions that are essential to human (cultural) survival (entire). Knowing, the sacred and culture are integral parts of human identity that find expression in daily life. The violent separation of classical scientific method from religion and culture was, at the time, a necessary but incomplete step. The emergence of a methodology of transdisciplinary is therefore, in evolutionary terms, an urgent and necessary adaptation or re-adjustment for western science.

However, western scientific knowledge is not an appropriate solution to every cultural survival and wellbeing problem. Human knowledge creation is culturally mediated and the free expression of different culturally mediated approaches to knowledge development is closely linked with the goal of cultural survival. A central goal of 'decolonising methodology' has been to obtain recognition for the legitimacy of culturally mediated worldviews, languages and approaches to knowledge development. The role of culture in mediating knowledge development is also a pre-requsite assumption that is needed to define and 
position an indigenous transdisciplinarity. Such an assumption is necessary because if we assume that western science is superior (i.e. the most valid model of knowledge development), then there can only ever be one 'superior' methodology of transdisciplinarity. Because this point is central to the conclusions of this paper, the remainder of this section is devoted to a more detailed consideration of why it seems reasonable to propose that western science is only 1 of an estimated 6,900 culturally mediated approaches to knowledge development that exist on planet Earth today [12].

\subsection{The Aetiology of Western Science}

What we today refer to as 'western' science is one small part of an accumulated knowledge continuum that has been contributed to by scholars of different cultural origins for thousands of years. The varied contributions of these scholars laid the foundations for the western scientific revolution. For example, it was the Sumerians who gave us the earliest forms of symbolic language [43]; the Babylonians who contributed to early forms of mathematics, astronomy [44-48], philosophy and the arts; the Persians who developed orderly government, complete with centralised administration, systems of communication and transport [49]; Ancient Greece gave us the first pre-industrial economy along with remarkable advances in philosophy, government, law, literature, astronomy, mathematics, medicine, technology, art and systems of education [50-61]; the Roman Empire developed Republican government along with advances in law, economics, architecture, engineering, literature, education, medicine and the arts [50, 6173] while finally, scholars of the Islamic Golden Age provided a linguistic bridge for the transfer of learning from Antiquity into Turkish, Hebrew and Latin languages. Islamic scholars also made remarkable advances in philosphy, mathematics, the natural sciences, engineering, medicine and the arts; advances that laid an important intellectual foundation for the western scientific revolution [74-79].

While terribly incomplete, this somewhat abbreviated, and yet remarkable history of 'culturally mediated' human knowledge development is a result of at least three pre-conditions that provide an important perspective from which to think about how we define 'western science'. First, human intellectual achievements have always been culturally mediated. Second, knowledge development needs freedom of expression because discontinuities in culture caused by war and other disturbance events interrupt culturally-mediated knowledge development processes, even though they can also provide opportunity for adaptation, novelty and innovation. Third, human contributions to knowledge developmemnt are not only culturally-mediated, they create culture in ways that transform reality. Cultural survival and wellbeing is both a 'cause' and 'consequence' of human knowledge development. This point is so important that it deserves further elaboration.

As far as we understand, from an western scientific perspective, the ability of humans to create knowledge sets them apart from other members of the animal kingdom. Humans are able to visually perceive and sense, reflect upon and change our perceptions of reality, with respect to time, in a way that grows knowing that we are able to store in memory and re-access. We have the ability to name, classify and group objects of visual and sensory perception in a way that creates a spatial (i.e. internal/external) awareness of our interaction with reality. While every human being is born with this innate capacity for knowledge development, the cultural context into which we are born provides an interpretive lens that strongly influences how we see the world and what knowledge we create [23].

Worldview is a sub-conscious collection of axiomatic reference points, or fundamental assumptions and beliefs about the nature of reality that we use as a pre-analytic basis for visual and sensory perception, reflection, evaluation and knowledge development. For the most part, we never question the validity of the worldview assumptions that are passed onto us as a consequence of the cultural context into which we are born. However, we are capable of becoming aware of inconsistencies in our worldview assumptions when we are provided opportunity (i.e. through natural experiments) to observe what happens when our worldview assumptions are pushed to their logical limits. While we generally assume that our worldview assumptions are irreducible (i.e. essential), correct, appropriate and valid (i.e. the way we see the world is a correct way to see the world), it is important to note that our worldviews are culturally mediated abstractions of reality, which in evolutionary terms, are adapted to a cultural and ecological context in which our survival and wellbeing must be achieved. Thus, worldview is itself, partly a product of culture. 


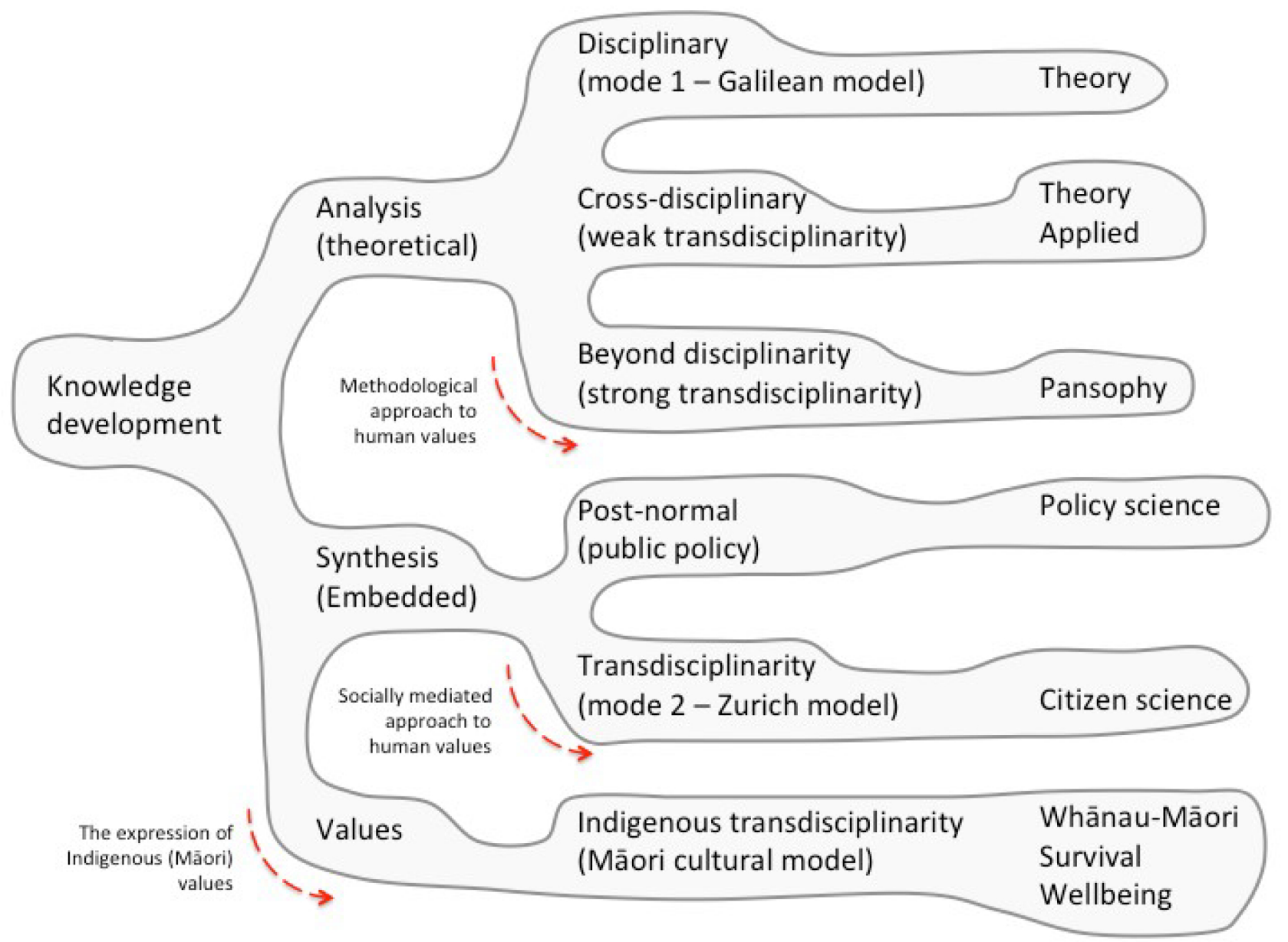

Figure 1: A visual depiction of the current theoretical landscape of transdisciplinarity.

Our worldview perceptions are encoded in the unique language of our culture. Language is the ultimate 'ontological' framework of $\left(\mathrm{Māori}^{2}\right)$ culture that provides a fascinating insight into our worldview assumptions $[12,80]$. We name what we perceive, while what we percieve is a logical consequence of our worldview assumptions. As such, language provides a useful diagnostic tool for inferring worldview assumptions. The distinctive language of a culture provides ontological building blocks, for the creation of knowledge through the use of culturally distinct epistemologies. Cultural knowledge is used on a daily basis to give expression to agreed cultural practices (i.e. values) which through the amazing creativity of culture transforms our world (Figure 1) in ways that create distintive 'cultural ecosystems, landscapes and nation states' [81]. A number of important conclu-

\footnotetext{
${ }^{2}$ A well known statement of Sir James Henare to the Waitangi Tribunal in 1989 clearly articulates this thought "Ko te reo te mauri o te mana Māori" (transl. language is the life force or energy of Māori).
}

sions follow from this thesis of culturally mediated, knowledge development activities.

First, human contributions to knowledge development are inextricably linked with our worldview. Furthermore, we are generally not aware of the extent to which our sub-conscious worldview assumptions and beliefs influence (i) how we 'see the world' and (ii) the nature of the knowledge we create. Second, culturally mediated knowledge development expands the expression of our cultural identity in ways that validate, refine and in some cases, fundamentally change that cultural identity. Cultural identity is constantly evolving and knowledge development thus plays a critical part in this process of change.

Third, it is important to re-iterate that every human being is born with an innate capacity for knowledge development. This is what might be referred to as 'knowledge development at its raw edge'. It is not necessary to obtain a $\mathrm{PhD}$ from university in order to become qualified to make knowledge development contributions to the survival and wellbeing of your 
culture and its distinctive identity.

Finally, our perceptions of reality are encoded in language that provides the ontological building blocks for knowledge creation. This point is important because there are a documented 6,900 languages in the world today [12]. This fact implies that there are also, at least, 6,900 different worldviews, perceptions of reality, knowledge traditions and cultural expressions of these systems of knowledge development that are responsible for the human cultural transformation of our world. In theoretical and methodological terms, this is the cultural landscape of transdisciplinary knowledge development.

Yet for some reason, we seem to have come to a time in human history in which there is an implicit, unquestioned assumption, that has become almost axiomatic among western scientists (i.e. that mode-1 western scientific methodology is 'the reference point' from which all other contributions to knowledge development should be evaluated or in some cases dismissed).

"In western cultures, to be involved in nonscientific knowledge production is to place oneself beyond the pale, so that there is, today, a distinct sense of social isolation associated with participation in a non-scientific activity..." [82, p. 2].

One of the defining challenges of 'decolonising' disciplinary science in New Zealand has involved an ongoing struggle for recognition of the legitimacy of a Māori cultural approach to knowledge development, education and spirituality [42]. This struggle is still very much 'work-in-progress' as is demonstrated by the following quote from a New Zealand Government policy document published in July 2007 that carries the name 'Vision Mâtauranga: unlocking the innovation potential of Māori knowledge, resources and people'.

Scientific knowledge has superseded traditional Māori knowledge in many ways, however, Mātauranga Māori contains suggestions and ideas that may yet make a contribution to research, science and technology (RSET), [83, p. 16].

This statement is problematic for a number of reasons. First, the idea that mātauranga Māori contains suggestions and ideas that may yet make a contribution to RSEST implies that research, science and technology is 'the reference point' to be used in assessing the relative worth or value of Māori knowledge. This begs the question of why it is not possible to use Māori cultural values and criteria to measure the worth or value of Māori cultural contributions to Māori knowledge development.

Second, western scientific knowledge is presented in this statement as having superseded traditional Māori knowledge. This claim ignores the fact that western science is itself only 1 of a documented 6,900 languages and culturally mediated approaches to knowledge development that exist in the world today [12]. To accept that western science has superseded one or all of the other 6,899 culturally mediated approaches to knowledge development begs the question of what criteria is being used to draw such a conclusion. How can we say, that one culture's worldview and perceptions of reality are in some way better or worse than another?

The role of culture in mediating the development of knowledge is important for another reason. An estimated $46 \%$ of the 6,900 languages that exist in the world today are at risk of extinction. What current research indicates, is that we are loosing one of these 6,900 languages, on average, every 3 months $^{3}$, so that within the next 100 years, we currently stand to loose somewhere between $50-90 \%$ of the world's current linguistic diversity [12]. Knowledge development is not just an end in itself. It supports the survival, continued evolution and wellbeing of human cultures. This knowledge development outcome is also important. It is within this cultural survival and wellbeing context, that justification exists for mapping the 'transdisciplinary' knowledge development experiences of different cultures and especially indigenous cultures.

\footnotetext{
${ }^{3}$ This estimate was derived from research completed by the Endangered Language Catalogue (ELCAT) project of the University of Hawaii. The initial findings of this research were presented at the 3rd International Conference on Language Documentation and Conservation in 2013. An online blog titled 'New estimates on the rate of global language loss' explains the derivation of this estimate and is avilable on the Rosetta Project website (http://rosettaproject.org/blog/).
} 


\section{The Landscape of Transdisciplinary Knowledge Development}

When it comes to transdisciplinary knowledge development and joint-problem-solving [84], the distance between indigenous cultures and western science might not be as far apart as we might have previously assumed. This realisation was first impressed upon my mind during the $2^{\text {nd }}$ World Congress on Transdisciplinarity in Brazil (2005), while listening to Basarab Nicolescu describe and explain his methodology of transdisciplinarity. I was surprised at the level of similarity, of resonance and signature that existed between Nicolescu's methodology of transdisciplinarity [9] and the knowledge development thinking and experiences of my tūpuna (transl. Māori ancestors).

Following the 2005 Congress, I read more widely on this topic and set myself to the task of attempting to characterise, and theoretically position these two knowledge traditions. With time, I gradually came to the realisation of distinct similarities and differences that made possible the characterisation of what I have referred to as an indigenous (Māori) transdisciplinarity. I have used the term 'indigenous' to suggest that the knowledge development traditions of my tūpuna, share similarities with other indigenous cultures. I have attempted to visually depict the current theoretical landscape of transdisciplinarity in Figure 1 and will devote the remainder of this paper to explaining the significance of this illustration.

Figure 1 focuses attention on the problem of 'knowledge development'. I use this name to include theorising, joint-problem-solving, experimentation and value-based approaches to knowledge development. Irrespective of the specific methods, or means used to create knowledge, Figure 1 recognises the existence of 3 main pathways of knowledge development (i.e. analysis, synthesis and values). Two of these pathways are well-known to western scientists (i.e. analysis and synthesis) and one is well-known to Māori and other indigenous peoples (i.e. a valuebased approach to knowledge development). These 3 pathways can be used to theoretically position, 3 different approaches to transdisciplinary endeavour.

First, in Figure 1, the analytical tradition can be characterised by 3 further pathways of knowledge development that have emerged as gradual adaptations of western scientific methodology (i.e. mode-1 sci- ence), as initially formulated by Galileo Galilei and others at the time of the western scientific revolution. This includes: (i) the emergence of distinctive areas of science and disciplinary specialisation, (ii) the co-ordination of knowledge development across and between the disciplines (i.e. what Max-neef [8] characterised as 'weak transdisciplinarity') and (iii) the simultaneous co-ordination of knowledge development - across, between and beyond the disciplines (i.e. what Max-neef [8] characterised as 'strong transdisciplinarity').

These 3 pathways are characterised by distinctly diferent goals. The creation of theory is the primary goal of disciplinary science, whereas the creation, and real-world application of theory is the primary concern of cross-disciplinary studies. Finally, the emergence of a methodology for the co-ordination of disciplinary knowledge development across, between and beyond the disciplines has opened a space for the unification of knowledge as a most recent adaptation of western science. I have characterised the 'strong transdisciplinary' goal by the use of the term 'pansophy' that appears to have been first used by Jan Amos Comenius (1592-1670). It was the lifelong ambition of Comenius to write what he called a 'pansophy' - a thesis that attempted to unify all knowledge. Comenius is known to modern educationalists as the 'Father of modern education' and in addition, appears to have been one of our early 'transdisciplinary' scholars [85-88].

An important characteristic of the 3 pathways of 'analytical knowledge development' depicted in Figure 1, is that its most recent innovation - the transdisciplinary methodology of Basarab Nicolescu (2005) - provides a methodological approach to the explicit reunificiation of western scientific object and subject.

Second, in Figure 1, the synthesis tradition of western scientific knowledge development can be subdivided into 2 additional pathays. The 'post-normal science' [89] and 'mode-2' pathways [82, 90-92], are further adaptations of classical western scientific methodology that provide additional approaches to the coordination of knowledge development across the disciplines. These 2 approaches have been spatially positioned as quite separate from the transdisciplinary methodology of Basarab Nicolescu. The reason for this separation is because the transdisciplinary methodology of Basarab Nicolescu is both an adaption of western science and a critique of the 
limitations of classical western scientific methodology.

By contrast, post-normal science and mode- 2 transdisciplinarity are based on an explicit assumption, that classical western scientific methodology is basically correct and does not therefore need revision, but application in new and novel ways [10]. Nicolescu has attempted to achieve the re-unificiation of the scientific subject and object through the creation of a new methodology for western science. By contrast, post-normal scientists and mode-2 transdisciplinary scientists attempt to achieve a co-creation goal, through the social mediation of scientific knowledge development (i.e. the explicit inclusion of disciplines, stakeholders and communities in the research process). While the methods used by mode- 2 transdisciplinary researchers and post-normal scientists differ, the overarching goal is to extend the coordination of knowledge development - across and between the disciplines - into the realms of (i) policy-making (i.e. policy science) and (ii) joint-problem-solving (i.e. citizen science). In Figure 1, I refer to the synthesis pathway of western science as 'a socially mediated approach to human values'.

Finally, an additional pathway for knowledge development is depicted in Figure 1, based on the explicit use of indigenous values as a means of creating knowledge. The analytical and synthesis pathways of Figure 1, depict the existence of differing adaptations of classical western scientific methodology that have been created in order to achieve the re-unification of scientific subject and object. An additional goal of the transdisciplinary methodology of Basarab Nicolescu has been the re-unification of knowledge. By contrast, the third pathway, located at the bottom of Figure 1 involves an approach to unified, holistic knowledge development, that is based on the expression of indigenous values. I have characterised this approach to knowledge development as 'indigenous transdisciplinarity' [93]. It is somewhat awkward and difficult to position an indigenous transdisciplinarity in theoretical proximity to the analytical and synthetic traditions of western science, because these 3 knowledge traditions do not share - to use western scientific language - a common linguistic basis. However, as noted earlier in this paper, I am increasingly impressed at the extent to which there are similarities of 'meaning' between indigenous transdisciplinarity and the transdiciplinary methodology of Basarab Nicolescu [9].
While listening to Basarab Nicolescu present his transdisciplinary methodology at the 2nd World Congress on transdisciplinarity, I had a sense of inner resonance, I could begin to see the visible signature of something with which I was already familier. Basarab Nicolescu explains this experience as communication between 'levels of perception' and 'levels of reality' that is made possible by the ' $\mathrm{T}$ state' or 'included middle'. Assuming this is correct, then it seems appropriate to describe the theoretical positioning of 'indigenous transdisciplinairty' in close proximity to western science, as the positioning of what western science has considered to date, to be logical contradictory pairs (i.e. A and non-A). The use of exclusive logic in this way seems appropriate given that it has been nothing short of a major struggle, for indigenous peoples to obtain recognition from western science as to the legitimacy of their knowledge traditions for no other reason than they are non-A (i.e. not western science). Yet, as I have attempted to show in this paper, western science does not hold a competitive monopoly on knowledge development when it comes to the problem of human cultural survival. This logical contradiction between the exclusive entities ('A' western science) and ('nonA' indigenous knowledge traditions) might finally be able to be reconciled through Basarab Nicolescu's logic of the included middle [9].

The goals of indigenous transdisciplinarity (Figure 1) seem to differ from those associated with western scientific methodologies. I am of course, most familiar with the experiences of my tūpuna (transl. Māori ancestors) in this regard. The central goal of Māori culture involves maintaining the survival and wellbeing of whānau Māori (transl. the Māori family ecosystem). To solve this survival and wellbeing problem, my tūpuna (transl. Māori ancestors) created what might be thought of (in English) as 'Māori universal values' (transl. kawa, kaupapa) [94]. A distinguishing characteristic of kaupapa (transl. Māori universal values) is that their daily expression sustained the survival and wellbeing of all members of whānau Māori (i.e. the Māori family ecosystem). When compared with the ecological destruction that has been associated with the application of western scientific knowledge over the last 170 years, the survival of my tūpuna (transl. Māori ancestors) on the New Zealand archapeligo for 800-1,000 years, before European settlement and colonisation was nothing short of a remarkable achievement. My 
reading of published literature, and in particular the most recent contributions of indigenous decolonising theorists, suggests that the survival and wellbeing experiences of my tūpuna (transl. Māori ancestors) over the last 1,000 years is consistent with the experiences of many other indigenous peoples. An elaboration of the experiences of my tuppuna (transl. Māori ancestors), and comparison with the trandisciplinary methodology of Basarab Nicolescu, is outlined in the 4th and final section of this paper.

\section{An Indigenous (Māori) Transdisciplinarity}

In this final section, I compare and contrast the knowledge development experiences of my tūpuna (transl. Māori ancestors) with emerging thinking on transdisciplinarity. In pursuing this writing goal, I cannot speak on behalf of Māori culture (entire), or all indigenous peoples. This paper is but a first step towards describing and theoretically positioning an indigenous (Māori) transdisciplinarity. It is written as a scholarly contribution towards dialogue between the western academy and the work of indigenous/Māori scholars and their communities.

The English word 'indigenous' is generally used to refer to one of two different meanings. When applied as a noun to human culture it generally refers to a genealogically related group of people whose identity is partly defined by an intimate inter-relationship with the natural world. When used as an adjective, it can be applied to any entity (including people) that originate 'naturally' in a particular place. While the English word 'indigenous' has been adopted by some Māori scholars [94], there are others who avoid the use of this English label. As a description of Māori culture, the meaning of indigeneity can be limiting in a way that fails to capture the unique and remarkable character of those human societies that have evolved distinctive cultural identities, in association with the Earth's island, forest, river, coastal, desert, arctic, marine, estuarine, wetland and grassland ecosystems.

As noted earlier in this paper, in exploring transdisciplinarity across cultural boundaries, it is the transfer of 'meaning' that is important. I agree that the English word 'indigenous' is limiting. However, its reference to the human $\equiv$ nature identity relationship, as a basis for cultural evolution, is a 'meaning' that is widely understood [95]. For this reason, I have used the term 'indigenous' as an English language approximation of a more complex, human social-cultural-ecological-spiritual reality [96-99] that is profound and worthy of our deepest respect.

In Figure 1, I have proposed that 'indigenous transdisciplinarity' is based on the expression of indigenous cultural values [100]. Before comparing and contrasting this approach to knowledge development with the transdisciplinary methodology of Basarab Nicolescu, it is important to explain the significance of an approach to human cultural knowledge development that is 'value-based'. As noted earlier, Māori scholars refer to this approach to knowledge development as 'kaupapa Māori research' [101] where the word 'kaupapa' has many possible 'contextual' meanings including the 'values of Māori society'. In the time of my tūpuna (transl. Māori ancestors), the goal of Māori knowledge development focused on the survival and wellbeing of whānau Māori (transl. the Māori family ecosystem). My tūpuna devised a plan for the achievement of this goal, that was based on the creation of 'kaupapa' or what might be explicitly defined in English as 'Māori (universal) values'. These values were passed across generations as kaupapa tuku iho (transl. inherited Māori values) and expressed through Māori behaviour called 'tikanga' (transl. right ways of doing things).

Kaupapa tuku iho (transl. inherited Māori values) are generally recognised by all Māori communities, however their expression as tikanga (transl. right ways of doing things) varies according to context, and to some extent the preferences and creativity of local Māori communities. Thus, kaupapa (transl. Māori cultural values) are 'universal' in the sense that all Māori communities recognise that these values form a basis for maintaining the survial and wellbeing of whānau Māori (transl. the Māori family ecosystem). For this reason, the daily expression of these inherited values in the form of tikanga (transl. right ways of doing things) forms a preferred basis for Māori knowledge development [102]. This approach to knowledge development ensured that knowledge discoveries were consistent with, or adaptations of, Māori cultural values and right ways of doing things. This in turn maintained the survival and wellbeing of whānau Māori (transl. the Māori family ecosystem).

Our tūpuna created, adapted and refined their kaupapa over a very long period of time as part of their knowledge development activities and in an attempt to discover what mixture of values would ensure the 
survival and wellbeing of Māori communities and what western scientists refer to as 'the natural world' (transl. whānau Māori). As noted above, these values have withstood the test of time, including 800 1,000 years of isolation on the island archapeligo of New Zealand, prior to British colonisation. The knowledge development activities of my tuppuna involved much more than the discovery of universal values. Their quest for survival and wellbeing led them to explore the mysteries of the universe, including what western scientists refer to as the 'quantum world'. While much of this escoteric knowledge has been lost as a conseuqnece of colonisation, wonderful insights still remain and provide a window into the world of Māori knowledge development before British colonisation (1840-). To illustrate this point, the following quote is presented. It was written by the late Rev. Māori Mardsen, who was privileged to have been one of the last of his generation to have attended the Whare Wānanga (transl. Māori schools of higher escoteric learning). Attendance at Whare Wānanga provided first hand access to the escoteric knowledge of our tūpuna (transl. Māori ancestors). After returning from overseas duty during the second world war, Māori Marsden recorded the following conversation.

After the war, when I returned to the Wānanga I was questioned by the elders of the Wānanga about my war experiences. In the course of my sharing our experiences I mentioned the atom bomb. One of the elders who had of course heard of the atom bomb asked me to explain the difference between an atom bomb and an explosive bomb. I took the word 'hihiri' which in Māoridom means 'pure energy'. Here I recalled Einstein's concept of the real world behind the natural world as being comprised of 'rhythmical patterns of pure energy' and said to him that this was essentially the same concept. He then exclaimed, "Do you mean to tell me that the Pākehā scientists (tohunga Pākehā) have managed to rend the fabric (kahu) of the universe?" I said "Yes" "I suppose they shared their knowledge with the tūtūa (politicians)?" "Yes" "But do they know how to sew (tuitui) it back together again?" "No!" "That's the trouble with sharing such 'tapu' knowledge. Tūtūā will always abuse it." [103, p. XIII]
How is it that my tūpuna (transl. Māori ancestors) were able to discover these (visually) hidden secrets of the quantum world, long before the tohunga Pākehā (i.e. western scientists) grappled with the troublesome discoveries of the quantum revolution in the 1920s [104-106]? While there is much that could be written in reponse to this question, in this paper I want to focus on three significant factors (i.e. cultural identity, isolation and epistemology).

First, concerning cultural identity. In Figure 2, I attempt to visually show that my tūpuna arrived at what I refer to as indigenous (Māori) transdisciplinarity as a result of their 'animistic' identification with the 'natural world' as a genealogical extension of the human Māori family. By contrast, what I have attempted to characterise in this paper as 'western culture' came to transdisciplinary methodology and practice as a result of attempts to extend (i.e. post-normal science and the Zurich model), [10, 89] and remedy (i.e. transdisciplinary methodology), [9] classical western scientific method. The journey of 'western culture' to classical scientific and transdisciplinary methodologies was mediated - not by 'indigeneity' - but by what I characterise as an 'urban ecology' (Figure 1). The concept of an urban ecology stands in contrast to the Māori family ecosystem. An urban ecology is a generalisation and abstraction of a more complex and so-called 'civilised' society [107] that used the creation of complex urban or city environments as evidence evolutionary superiority [31]. Thus, indigenous and western scientific transdiciplinarity have distinctly different aetiologies.

Second, concerning isolation. ${ }^{4}$ The evolution of western society over the last 3,000 years occurred primarily in the northern hemisphere. Reference to the modern-day preface 'western' denotes the emergence of a contemporary cultural identity from interaction among many geographically related cultural entities. Modern 'western' society is a culturally co-created phenomenon. By contrast, my 'tupuna' lived in relative isolation from this turbulent cultural evolution in the northern hemisphere. They dwelt on island ecosystems in the southern oceans. This home afforded then a wonderful 'natural laboratory' and opportunity for knowledge development that was not influenced by 'western' thought.

\footnotetext{
${ }^{4}$ I am deeply grateful to my whānaunga and rangatira, Whatarangi Winiata for drawing my attention to this important dimension of the whānau experiences of my tūpuna.
} 


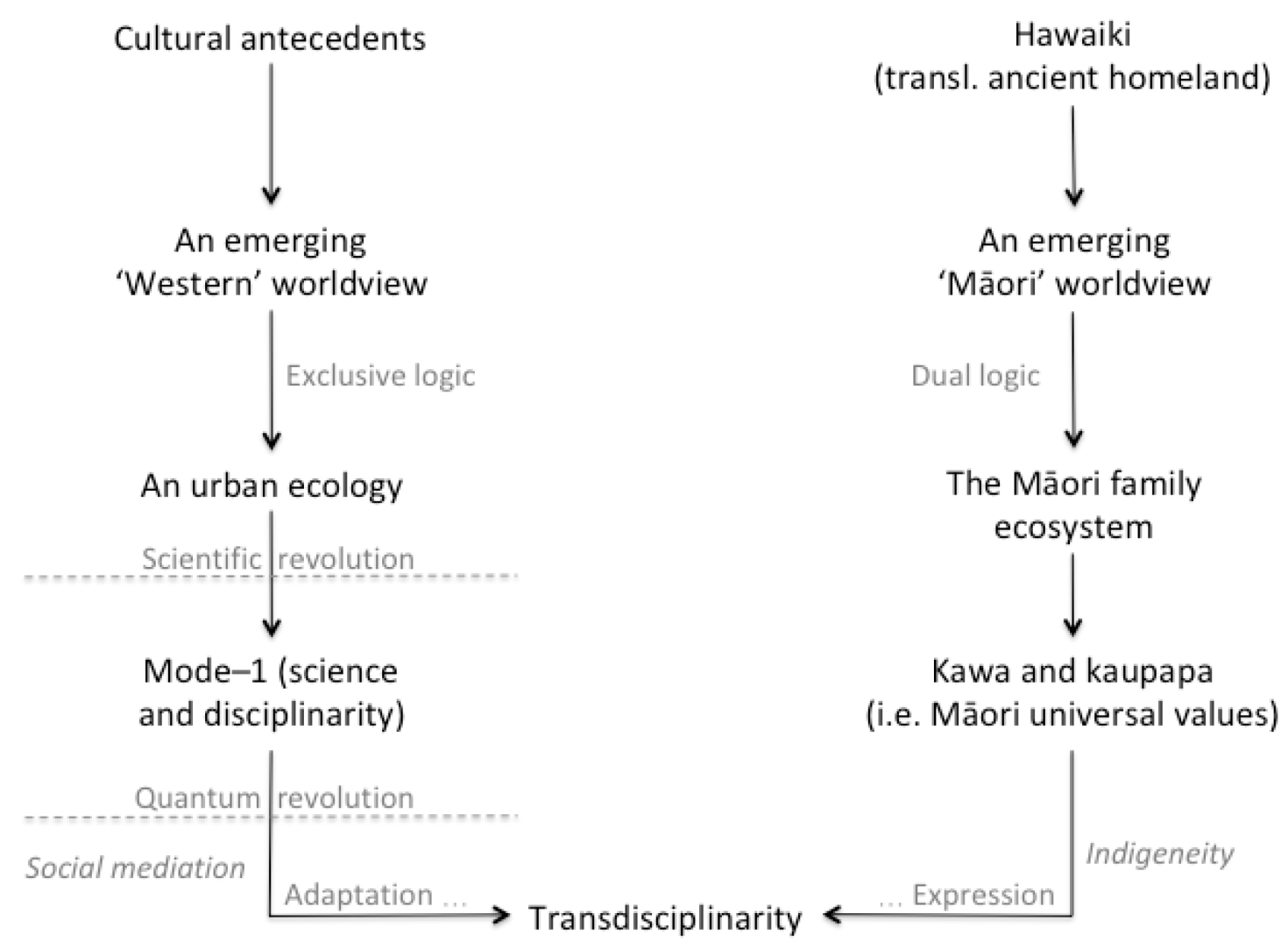

Figure 2: A visual depiction of 2 different evolutionary pathways to transdisciplinarity.

Finally, concerning epistemology. The latest methodological developments in western science (i.e. transdisciplinary methodology) shares similarities with the knowledge development traditions of my tūpuna. I hesitate to refer to indigenous transdisciplinarity as a 'methodology' because it involves an approach to knowledge development that is - in one sense - distinctly different to that of western science (i.e. based on the expression of inherited Māori (universal) values), [108]. My use of the word 'methodology' is only to draw attention to the existence of similarity. Thus, this linguistic concession is for the benefit of communication with western scientists and not as an ontological contribution towards mātauranga Māori (transl. Māori knowledge). While indigenous transdisciplinarity is distinctive, it is possible, through the logic of the "included middle" proposed by Basarab Nicolescu, to align this Māori cultural 'reality' with certain levels of western scientific perception. To explore this included middle: (i) I comment (below) on the unification of classical scientific subject and object and then (ii) I use the transdisciplinary axioms of Basarab Nicolescu [9] as a conceptual and theoretical reference point (i.e. sub-section headings) for 'sketching' a written outline of indigenous (Māori) transdisciplinarity, drawn primarily from the writings of the late Rev. Māori Marsden [103].

\subsection{On the Unification of Classicial Scientific Subject and Object}

I often pondered why my tūpuna (transl. Māori ancestors) saw no need for a written language. There is much that could be written in comment on this question. However, an important point is that the knowledge development goals (i.e. the survival and wellbeing of the Māori family ecosystem) of my tūpuna (transl. Māori ancestors), required the creation of systemic, holistic knowledge in which subject-objectsacred are unified. A real challenge faced by my tūpuna (transl. Māori ancestors) was how to communicate subject-object-sacred knowing of this kind from one generation to the next - with accuracy. This problem was solved with the aid of oral communication [109]. Written language is a discretised, simplificiation of reality, much like the number system in mathematics. It cannot easily be used to 
communicate subject-object-sacred meaning from 'writer' to 'reader' without introducing the problem of human perceptual complexity. By contrast, oral language, when used in conjunction with communication aids (e.g. time, location, experience, smells, tonal variation, facial expressions and guestures) can transfer subject-object-sacred meaning more effectively [110].

My tūpuna (transl. Māori ancestors) were masterful in their use of oral language in conjunction with other communication aids that were used to transfer knowing that embodied subject-object-sacred dimensions. Māori oral language was also expressed in numerous symbolic forms including toi (transl. artistic expression), haka (transl. a form of dance), waiata (transl. lyric and melody), pakiwaitara (transl. stories), pūrākau (transl. myths, legends), whakapapa (transl. genealogies) and whakatauākì (transl. wise sayings). My tūpuna (transl. Māori ancestors) saw no need for a strictly objective knowing of reality [103, p. 2]. Their approach to reality was collectively mediated, systemic, distinctly holistic and deeply profound. As such, their systems of knowledge development along with the storage and transfer of subject-object-sacred knowing across generations aligns with what Basarab Nicolescu [9] identitifed as a core goal of transdisciplinarity (i.e. the re-unification of scientific subject and object).

The axiomatic foundation of classical western scientific methodology assumed the existence of universal laws, that could be mathematically characterised with the aid of experimental replication [111]. However, as Basarab Nicolescu [9] notes, human ontologies can include, but are not limited by mathematical characterisation. Thus, a transdisciplinary methodology cannot be used to approach the totality of human knowledge, if limited to the language of mathematics. In this connection, it is interesting to note that my tūpuna saw no need for a written numerical or symbolic language. It was the Christian missionaries who were responsible for systematising the oral traditions of my tupuna as a written language, and this included the assumed relevance of a number system. ${ }^{5}$

\footnotetext{
5'History of the Māori language', URL: https://nzhistory. govt.nz/culture/maori-language-week/history-of-themaori-language, (Ministry for Culture and Heritage), updated 10-Oct-2017.
}

\subsection{The Ontological Axiom of Transdisciplinarity (Basarab Nicolescu)}

\author{
There are, in Nature and in our knowledge \\ of Nature, different levels of reality and, \\ correspondingly, different levels of percep- \\ tion $[9$, p. 9].
}

In Te Reo Māori (transl. the Māori language) there is no simple linguistic equivalent for the English word 'reality'. This is partly a consequence of differing worldview assumptions. My tūpuna did not employ exclusive logic to differentiate between living and non-living entities. Earth, sky and all of the entities of the natural world were members of whānau Māori (i.e. the Māori family ecosystem) and thus interdependently related by whakapapa (transl. genealogy). Thus, what western scientists call 'an experimental approach to reality' - was for my tūpuna (transl. Māori ancestors) - part of a ritualistic dialogue with family members. Despite this distinctly different ontology, the transdisciplinary axiom of 'levels of reality' that correspond to 'levels of human perception' seems to have been known by my tūpuna (transl. Māori ancestors).

First, my tūpuna (transl. Māori ancestors) employed pūrākau (transl. mythology, legend) to symbolically describe the highest level of intellectual attainment as 'Toi o ngā rangi' (transl. the summit or highest place of Ranginui our Sky father). The ascent to this summit of learning was first completed by one of the children of Papatūannuku (transl. our Earth mother) and Ranginui (Transl. our Sky father) named Tāne (trans. husband, male, man). To ascend to 'Toi o ngā rangi' (transl. the summit or highest place of Ranginui our Sky father), Tāne (trans. husband, male, man) had to climb his way through eleven levels of attainment, which each carry a distinctive name and meaning. This narrative, was to impress upon us that the expression of pūkengatanga (transl. the acquirement of specialist or expert skills and knowledge) involved a search for ever deeper levels of knowing [103]. These levels of knowing partly involve coming to terms with distinctly different Māori realities as symbolised by the 3 baskets of knowledge explained next.

Second, in Te Ao Māori (transl. all things in Māori worlds) discontinuities in space and time exist between different levels of knowing and reality. This understanding is symbolised by the meaning of 3 
baskets of knowledge (transl. Ngā kete e toru) that were given to Tāne (trans. husband, male, man) when he reached 'Toi o ngā rangi' (transl. the summit or highest place of Ranginui our Sky father). These 3 baskets of knowledge (transl. Ngā kete e toru) contained all of the learning that my tūpuna would need to (i) maintain their collective survival and wellbeing and (ii) explore the deeper mysteries of the universe. The 3 baskets draw our attention to 3 different worlds (cf. levels of reality) that the late Rev. Māori Marsden [103] describes as the 3 worldview of the Māori. In other words, as Māori, we view the world (cf. reality) by simultaneously bringing together 3 completely different perceptions of reality, that correspond to 3 different worlds, that are symbolised by Ngā kete e toru (transl. the 3 baskets of knowledge).

In the first basket of knowledge - 'Tua-uri' (transl. beyond in the world of darkness) - there exists the "the real world of the complex series of rhythmical patterns of energy which operate behind this world of sense perception" [103, p. 60]. It is within the realm of Tua-uri that the evolution of the physical 'sensible world' emerges as a space-time framework [103].

The second basket of knowledge - Te Aronui (transl. as that before us) - corresponds to what the late Rev. Māori Marsden referred to as the "... world before our senses" [103, p. 61]. An important lesson from the 3 baskets of knowledge is that the world of sensory perception (what western scientists refer to as the macro-physical world) does not contain a complete explanation of causality. Much of what emerges in the sensory world is a direct result of flows of energy in the domain of Tua-uri (transl. beyond in the world of darkness). These energy flows find expression in Te Aronui (transl. the world of sensory perception), [103].

The name of the third basket of knowledge is Te Ao Tua-âtea (transl. the world beyond space and time). As the Rev. Māori Marsden explains:

$\bar{A}$ tea is the word for space; it is usually combined with wā (time) to form wātea (space-time). They (our ancestors) saw space and time as conjoined together and relative to each other... This is the eternal realm, which is before Tua-uri and towards which the universal process is tending. The worlds both of Tua-uri and Te Aronui are part of the cosmic process. And if the uni- verse is process, it is more akin to life, mind and spirit, which are obviously processes. Therefore the world of sense perception, the natural world around us is unlikely to be ultimate reality. For the Maori, Tua-ātea, the transcendent eternal world of the spirit, is ultimate reality [103, $p$. 61-62].

The 3 baskets of knowledge depict different worlds (cf. levels of reality) that our tūpuna used as a basis for enriched perception. I find it very interesting that only 3 baskets of knowledge are mentioned in the narrative that describes the knowledge that was given to Tāne (trans. husband, male, man) in 'Toi o ngā rangi' (transl. the summit or highest place of Ranginui our Sky father). Yet the late Rev. Māori Marsden draws our attention the existence of a fourth world.

To the three baskets containing the knowledge of the three worlds we must add a fourth world, the world of symbol. The world of symbol is a deliberate creation of the human mind. Man creates symbols to depict, represent and illustrate some other perceived reality. Words, formulae, forms, ritualistic ceremonies, legend and myth are created by the human mind as maps, models, prototypes and paradigms by which the mind can grasp, understand and reconcile the worlds of sense perception and the real world behind that [103, p. 62].

The narrative of the 3 baskets of knowledge provides an interesting parallel to the $1^{\text {st }}$ axiom of Basarab Nicolescu (2005):

There are, in Nature and in our knowledge of Nature, different levels of reality and, correspondingly, different levels of perception $[9, p .9]$.

The 3 baskets of knowledge could be thought of as differing levels of reality that collectively compose a cosmic process. The 4 th world of symbols, corresponds to levels of human perception. The training needed to enhance different levels of Māori perception so that they could gain access to different levels of reality (cf. worlds) was the task of the Whare Wānanga (transl. a school of higher escoteric learning). While in the time of my tuppuna 
(transl. Māori ancestors), Māori knowledge was not organised around the contributions of different areas of (disciplinary) specialisation, mātauranga Māori (transl. Māori knowledge) was not entirely without structure. The escoteric schools of learning (i.e. Whare Wānanga) were staffed by tohunga (transl. experts, senior scholars) who took responsibility for different classes of knowledge and contributed towards growing it. Each tohunga was a gifted spiritual leader and possessed natural ability to communicate between the spiritual and temporal realms through karakia (transl. ritualistic dialogue), pātere (transl. ritualistic chants) and/or waiata (transl. lyrical narrative). The training of differing perceptive facilties is evidenced by the various offices of tohunga (transl. experts, senior scholars), whose abilities overlap in some areas, but were also aligned to differing baskets of knowledge (cf. levels of reality), [103].

Tua-uri (transl. beyond in the world of darkness) - the tohunga karakia specialised in rituals including the manipulation of mauri (transl. a pure form of energy responsible for bonding all things together). The tohunga whakapapa developed extensive knowledge of genealogy and thus understood the power of relationships in maintaining the whāriki (transl. fabric or weave) of Te Ao Māori (transl. all things in Māori worlds). It was the duty of the tohunga whakapapa to foster, maintain, and when necessary, repair relationships [36, 37, 103].

Te Aronui (transl. as that before us) - the survival and wellbeing of whānau Māori (transl. the Māori family ecosystem) in the world of sensory perception (transl. Te Aronui) involved the perceptive skills of the tohunga whakairo (transl. specialist in carving), the tohunga tā moko (transl. specialist in tattoo), the tohunga kōkōrangi (transl. specialist in astrology), the tohunga tito waiata (transl. specialist in lyrical narrative), the tohunga tārai waka (transl. specialist in canoe making) and the tohunga ahurewa (transl. ritual mediator), [36, 37, 103].

As my tūpuna (transl. Māori ancestors) used oral language and communication aids to transfer knowing across generations, they likewise applied symbolic subject-object-sacred skillfulness to everything they created. For example, whare (transl. buildings) and waka (transl. canoes) were carefully designed and constructed with remarkable artistic skill and carved adornment that made it possible to give visual expression within the world of human sensory perception (transl. Te Aronui) to the hidden worlds of Tua-uri (transl. beyond in the world of darkness) and Te Ao Tua-âtea (transl. the world beyond space and time).

Te Ao Tua-ātea (transl. the world beyond space and time) - the tohunga ahurewa (transl. ritual mediator) was a specialist in communication between worlds, in particular the various members of whānau Māori (transl. the Māori family ecosystem). This involved the acquirement of sacred knowledge, spiritual beliefs, customs and extensive knowledge of genealogy. As such, the tohunga ahurewa (transl. ritual mediator) was able to give advice about Māori community endeavours $[36,37,103]$.

The existence of differing levels of reality and corresponding levels of perception in Te Ao Māori (transl. all things in Māori worlds) also resonates with a number of the theoretical postulates of Basarab Nicolescu [9].

First, in moving from one basket of knowledge to the next, there exists a discontinuity in logic and the space-time framework. So much so that it required evidence of giftedness and training by tohunga (transl. experts, senior scholars) to develop the perceptive skills needed to communicate and work within the worlds of Tua-uri (transl. beyond in the world of darkness) and Te Ao Tua-ătea (transl. the world beyond space and time). Beyond these specialist skills of the tohunga, daily activities in Māori communities were interdependently related with these 'worlds beyond' through the expression of kaupapa tuku iho (transl. inherited Māori values), the expression of tikanga (transl. right ways of doing things) and karakia (transl. ritual dialogue).

Daily activities within Te Aronui (transl. as that before us) - the world of sensory perception - also required the development of perceptive facilities related to daily interactions with Atua (transl. the children of Papatūānuku and Ranginui) who are the kaitiaki (transl. guardians, caretakers) of the various domains (cf. ecosystems) of this world of sensory perception. Development of sensory perception was possible by traversing the 12 levels of deeper learning symbolicly depicted in the journey of Tāne (trans. husband, male, man) to 'Toi o ngā rangi' (transl. the summit or highest place of Ranginui our Sky father). The following story from the Rev. Māori Marsden about early fishing experiences nicely illustrates this point.

As children we often went fishing both in the harbour and in the open sea with mem- 
bers of the tribe. My father was always consulted. He would quickly calculate the day according to the Maori lunar calendar, the state of the tide, the direction of the wind and other phenomena. He would then advise us what reefs, or grounds to fish and the best times according to the state of the tide. He would advise against going to other grounds, which were handier or more popular as a waste of time. He would give us the reasons. By the time we were young men we had imbibed a lot of this traditional lore. Often we tested this knowledge and found it trustworthy [103, p. 61].

Second, it is evident from this more escoteric knowledge provided in the writings of the late Rev. Māori Marsden, that no one position within these various worlds or levels of reality constituted a 'privileged place' from which to perceive the totality of all levels of this 3 worldview. Consistent with the postulates of Basarab Nicolecu, within this Māori conception of the world, a single level of reality exists, because all levels of reality co-exist at the same time. Thus, the notion of theoretical superiority appears to have been foreign to my tūpuna.

A distinguishing characteristic of Māori society, even today, after 170 years of the damaging effects of colonisation, is that quite different perceptions of the same reality 'co-exist' within Māori society and this phenomenum is not thought unusual. It is however, a cause of great confusion for western scientists who start dialogues with Māori communities while intuitively looking for 'superior explanations' My tūpuna had a deep respect (cf. sacred regard) for Te Ao Māori (transl. all things in Māori worlds) and seemed to comprehend that there was little to be gained in arguing over the merits of one persons 'world' perceptions in relation to another's. Instead, they embraced all perceptions, and respected difference. This is especially evident when we consider the kaupapa and tikanga that guided 'collective' knowledge development [103, p. 35]. In this sense, Māori knowledge remains forever open. Consistent with what Basarab Nicolescu (2005) has postulated in regards to transdisciplinary knowing, the full depths of the 3 baskets of knowledge and the 12 levels of knowledge attainment will never be exhausted, nor confined to one self-enclosed theory.

\subsection{The Logical Axiom of Transdisciplinarity (Basarab Nicolescu)}

The passage from one level of reality to another is insured by the logic of the included middle [9, p. 9].

In Te Reo Māori (transl. the Māori language) there is no linguistic analogue for the 'included middle'. However, it is equally clear to me that 'meaning' relating to the existence and critical importance of a 'T-state' or 'included middle' was not unfamilar to my tūpuna. I draw this conclusion from many lines of thought and experience including the following.

First, it is important to reiterate that the 'logic of the included middle' is a recent adaption of the 'classical western scientific logic' of the excluded middle, with its contradictory pairs: A and non-A. Exclusive logic forms the basis of all of the systems of categorical classification in western science, and the discretisation of a number system in mathematics. Dependence on the use of exclusive logic in western science has resulted in breath-taking analytical achievements. However, the western scientific world - beginning at the time of the quantum revolution has had to come to terms with the fact that exclusive logic, while not wrong, is by itself an incomplete logic.

The limitations of the logic of the 'excluded middle' for achieving the goals of whānau Māori (transl. the Māori family ecosystem) survival and wellbeing appear to have been recognised by my tūpuna. My tūpuna (transl. Māori ancestors) saw a place for exclusive logic. This point can be illustrated by drawing attention to 'tap $\bar{u}$ ' (transl. sacred) and 'noa' (transl. common) categories (cf. A and non-A) in Te Reo Māori (transl. the Māori language). However, by drawing attention to the existence of exclusive logic in Māori language, it is important to note, that the use of this logic does not effectively define or characterise the centre-of-gravity of 'logic' in Māori culture. While exclusive logic has been the dominant logic of classical western science, it is not the dominant logic of Māori culture. The 'inherited Māori universal values' of Māori culture (i.e kaupapa tuku iho) are dependent for their existence and expression on the use of inclusive logic. To use western scientific langauge, my tūpuna (transl, Māori ancestors) had a 'dual theory of logic' in which inclusive logic was the dominant logic of Māori culture. 
Second, a moments reflection will lead to the realisation that the knowledge development goals of my tūpuna (i.e. the survival and wellbeing of the Māori family ecosystem) could not be achieved without inclusive logic. This is because, survival and wellbeing goals are systemic and holistic in nature, in a way that was needed to protect - the integrity of what anthropologists refer to as the human $\equiv$ ecosystem identity relationship - that is the central pillar of the Māori family ecosystem concept. My tūpuna (transl. Māori ancestors) used their '3-world' island ecosystem home to co-create and co-adapt kaupapa (transl. inherited Māori universal values) in a way that made possible the simultaneous achievement of both human and ecological survival for approximately 800-1,000 years.

Finally, the role of 'knowledge co-creation' in Māori survival and wellbeing provides a fascinating insight into the awareness of my tūpuna (transl. Māori ancestors) of the importance of an 'included middle'. It it difficult to characterise Māori cultural knowledge co-creation processes from the perspective of scientific method a priori. This is because Māori knowledge creation processes are 'open' and 'socially mediated'. In other words, both the problem to be solved (collectively) and the means by which a problem is to be solved (i.e. what western scientists refer to as 'method') are generally unknown at the beginning of a collective, Māori knowledge development process. The success of a socially mediated knowledge development process of this kind is dependent on 2 critical factors.

Finally, the role of 'knowledge co-creation' in Māori survival and wellbeing provides a fascinating insight into the awareness of my tuppuna (transl. Māori ancestors) of the importance of an 'included middle'. It it difficult to characterise Māori cultural knowledge co-creation processes from the perspective of scientific method a priori. This is because Māori knowledge creation processes are 'open' and 'socially mediated'. In other words, both the problem to be solved (collectively) and the means by which a problem is to be solved (i.e. what western scientists refer to as 'method') are generally unknown at the beginning of a collective, Māori knowledge development process. The success of a socially mediated knowledge development process of this kind is dependent on 2 critical factors.

First, the members of a Māori community ensure that the collective resolution of a problem, or the co-creation of knowledge is guided by the expression of kaupapa tuku iho (i.e. inherited Māori values). The expression of kaupapa tuku iho (i.e. inherited Māori values) as tikanga (transl. right ways of doing things) should not be confused with the application of 'methods' or 'processes'. In a socially mediated dialogue, that can appear random and directionless at times, the behavioural expression of Māori cultural values occurs in real-time. Thus, the concept of a a priori method is not helpful in describing or understanding this phenomenon.

Second, the fact that differing perceptions of the same reality are allowed to co-exist in Māori culture, provides a rich source of human perceptual access to differing levels of reality that can, in turn, be used to co-create and in some cases collectively stumble across previously unseen $\mathrm{T}$-states (i.e. what Basarab Nicolescu (2005) refers to as the included middle). In this way, Māori knowledge co-creation is able to open and connect streams of consiousness between neighbouring levels of reality and human perception, in ways that resolve the logical contradictions that are a consequence of human perception based solely on the use of exclusive logic at one level of reality. Again, exclusive logic is not wrong, but it can only ever provide incomplete human perceptions of reality. This is because exclusive logic is, by its very nature, intolerant of inclusion.

In Māori culture, co-creation of knowing through the logic of the included middle is also beautifully illustrated in the meaning of the word 'ako' (transl. to learn, study, instruct, teach, advise). The Māori word used for 'learning' can also be used to refer to instructing, teaching or advising. Both exclusive and inclusive logics co-exist in the same word to describe a model of education in which 'student (A) and teacher (non-A)' can simultaneously be teacher (A) and student (non-A). This reconciliation of what are considered to be mutually exclusive A (i.e. student) and non-A (i.e. teacher) categories in western education is achieved through recognition of the fact that both student and teacher have epistemic access to different levels of reality and perception. Thus, their collective perceptions can be used to co-create knowing based on the mutually interdependent expression of Māori cultural values. 


\subsection{The Complexity Axiom of Transdisciplinarity (Basarab Nicolescu)}

The structure of the totality of levels of reality or perception is a complex structure: every level is what it is because all the levels exist at the same time $[9$, p. 9].

Co-creation of knowing, a 3 worldview, recognition of the existence of differing levels of perception and reality, along with the adoption of a dual theory of logic means that the knowledge development activities of my tūpuna (transl. Māori ancestors) also contributed towards a certain Māori cultural knowing of complexity. Western scientific notions of complexity are not easy to translate using the vocab of Te Reo Māori (transl. the Māori language) and this includes the complexity categories postulated by Basarab Nicolescu (2005), (i.e. horizontal, vertical and transversal). However, a Māori knowing of complexity exists and can be approached by focusing attention on differing aspects of Māori 'culture' as explained below.

In Maori terms then, culture is that complex whole of beliefs, attitudes, values, mores, customs, knowledge acquired, evolved and transmitted by his society as guiding principles by which its members might respond to the needs and demands dictated by life and their environment [103, p. 34].

First, the expression 'Te Ao Māori' (transl. all things in Māori worlds) draws attention to Māori cultural complexity (i.e. all that is included in the 3 Māori worlds). A distinguishing characteristic of this Māori notion of 'complexity' is that it is based in Māori cultural (i) systems of belief, attitudes, values, mores, customs, knowledge acquired, evolved and transmitted as a basis for responding (ii) to the needs and demands dictated by life and their environment. Thus from a Māori perspective, the human perception of reality - what the late Rev. Māori Marsden refers to as the world of symbols (i.e. belief, attitudes, values, mores, customs) - is a constituent part of 'all things Māori' (i.e. complexity). This conception of Māori complexity is consistent with the vertical complexity category of Basarab Nicolescu (2005).
Second, as noted earlier, a Māori cultural model of complexity, in western scientific terms, does not isolate the 'subject', 'object' and 'sacred'. Furthermore, what western scientists refer to as the 'scientific subject', in Māori cultural terms, would not be considered as an individual observer. Instead, the Māori 'subject' symbolises a collective that uses the creative power of the 'included middle' to fashion new knowing that is, irreducible, in terms of its relationship to pre-existing knowing. Furthermore, dependence on an oral language to store and transfer subjectobject-sacred knowing across time ensured that the mana (transl. status) and integrity of subject-objectsacred knowing (cf. complexity) was maintained from one generation to the next. Subject-objectsacred knowing corresponds to the horizontal and vertical complexity categories of Basarab Nicolescu (2005).

Third, it is not possible to explore a Māori conception of complexity without making mention of whakapapa (transl. genealogy, genealogical table, lineage, descent). Whakapapa (transl. genealogy, genealogical table, lineage, descent), would have to be the ultimate symbolic representation of Māori cultural complexity that traces our genealogy back to Papatūānuku (transl. our Earth mother), Ranginui (transl. our Sky father) and Atua Māori (transl. the children of Papatūānuku and Ranginui) in a way that includes associated features, plants and animals of the natural world. Whakapapa (Transl. genealogy, genealogical table, lineage, descent) provides a powerful symbollic representation of the temporal and organisational complexity of whānau Māori (transl. the Māori family ecosystem) that was used extensively in Māori society to establish lineage (as a claim to leadership), land, fishing rights and status $[36,37]$. It was also used by kaitiaki (transl. guardians, caretakers) to monitor the development and wellbeing of whānau Māori (transl. the Māori family ecosystem). Whakapapa thus partly corresponds to the transversal complexity category of Basarab Nicolescu (2005).

Fourth, oral language and vocabulary (cf. ontology) also support a Māori cultural conception of complexity. The importance of this relationship cannot be over-stated. Dependence on exclusive logic has had a dramatic affect on the English language. According to online sources ${ }^{6}$, there are now in excess

\footnotetext{
${ }^{6}$ No. of words in the English language', https://www. languagemonitor.com/. According to the online language
} 
of 1 million words in the English language and this includes the entire specialist vocab libraries associated with western scientific disciplinary specialisations. By contrast, the core vocabulary of the Māori language is approximately 600 words. This does not include the existence of English loan words and transliterations. The evolution of language based on exclusive logic can only lead to ever increasing levels of disaggregation (cf. specialisation) in academic disciplines and the English language itself. By contrast, the dominant use of inclusive logic in Te Reo Māori (transl. the Māori language) resulted in the aggregation of meaning into a comparatively small, core, and multivalent vocabulary. Why didn't our tūpuna invent thousands of new core vocab constructs to assist them in accurately describing their complex cultural perceptions of reality?

The answer to this question lies partly in the central role of inclusive logic in Māori culture and the fact that the goal of unifying knowledge is also important to Māori communities. Mātauranga Māori (transl. the corpus of Māori knowledge) is unified in a way that is not inconsistent with the existence of vertical complexity (the co-existence of differing human perception of reality). This knowledge unification goal could be achieved because 'explanatory superiority' was not the central objective of Māori knowledge creation. It was instead, the emergence of perceptual creativity, māramatanga (transl. enlightenment) and mōhiotanga (transl. experiential knowing) through the logic of a Māori included middle.

Finally, the goal of Māori knowledge unification can be illustrated by drawing attention to an interesting characteristic of the co-creation of knowledge in what I have suggested is a Māori 'included middle'. While involved in co-creating knowing, how do the members of a Māori community collectively 'know' that a 'T-state' has been discovered? The answer to this question is that the presence of wairua (transl. the spirit of a person that exists beyond death) becomes evident in the form of collective 'resonance' or 'agreement'. Wairuatanga (transl. a collective experience in wairua) involves a 'collective knowing' that is beyond disciplinarity. I draw attention to this phenomenon, partly because of the derivation of the word 'wairua' - wai (transl. water) and rua (transl. two) as literally 'two waters'. Thus, in Māori

monitor, the English language passed the 1 million word threshold on the 10th of June, 2009 at 10.22am (GMT) cultural terms, the 'included middle' is a meeting place of 2 sacred waters (i.e. the sacred waters that flow from levels of reality and the sacred waters that flow from levels of human perception). The meeting of these sacred waters creates 'resonance'. This insight also draws attention to the fact that a Māori cultural experience of the included middle is necessarily based on the simultaneous perception of the 3 worldview of the Māori [39].

\section{Concluding Comments}

This paper draws on key characteristics of New Zealand Māori cultural experiences in knowledge development to define what I describe in English as an indigenous (Māori) transdisciplinarity. There are a number of points, worthy of mention that follow from this paper. First, there has been a tendency on the part of western scientists to view cultural contributions to knowledge development as 'non-science' (i.e. non-A). While this classification is technically correct, in terms of the use of the logic of the excluded middle (i.e. A and non-A), it is both wrong and unhelpful to draw from this categorisation the conclusion that culture has no legitimate or valid role to play in knowledge development. As I have attempted to show in this paper, the survival and wellbeing of the human family on planet Earth is ultimately a problem of cultural survival and wellbeing. It is none-other than the world's 6,900 cultures that are best qualified to solve their own cultural problems. Culturally mediated human knowledge development is thus crucial to human cultural survival and wellbeing.

Second, it is equally unhelpful to hold the view that western scientific knowledge, methodology and methods have in some way superceeded or surpassed the knowledge development traditions of the world's cultures and in particular the world's indigenous cultures. This conclusion is both irrelevant (because it is lacks valid evaluation criteria) and in the case of New Zealand Māori, factually incorrect. What I have attempted to show in this chapter is that at the time of first arrival of Captian James Cook in New Zealand, in 1769, the knowledge development activities of my tūpuna were at least 216 years ahead of comparative theoretical and methodological developments in western science [i.e. 112].

Third, the knowledge development traditions of my tūpuna (transl. Māori ancestors) sustained 
whānau Māori (transl. the Māori family ecosystem) on this island archipelago for approximately $800-1,000$ years. In New Zealand at least, this is the only 'time proven' model of human and ecological sustainability that we currently have. By comparison, the introduction and eventual dominance of a western model of science and market economy has led to a rapid decline in the wellbeing of whannau Māori (transl. the Māori family ecosystem) - in some cases to critical threshold values - in other cases to the point of extinction.

For a small country, with a relatively small population, our ecological performance over the last 170 years in terms of species extinctions, deforestation, the destruction of wetlands, overharvesting of marine ecosystems, the pollution of inland waterways and the destruction of Māori communities is nothing to boast about. A very real challenge facing Māori communities today is the realisation that whatever western science and the market economy had to offer, they have so far not demonstrated the ability to maintain the survival and wellbeing of whānau Māori (transl. the Māori family ecosystem). The decolonisation of western science that started in the late 1990s has provided a partial remedy to this problem. However, attention must now be turned to the decolonisation of capitalism and the market economy, as a Māori cultural (cf. indigenous) imperative for achieving the (now) future goal of cultural survival and wellbeing.

Fourth, this chapter provides an initial attempt to characterise and theoretically position the knowledge development activities of Māori scholars and communities in relation to mode-1 (disciplinary science), mode -2 transdisciplinarity (i.e. the Zurich model) and strong transdisciplinarity (i.e. the transdisciplinary methodology of Basarab Nicolescu 2005). In New Zealand, an ongoing struggle with the Government, large businesses, universities and research institutions for recognition of the legitimacy of Māori contributions to knowledge development is set to continue for some time to come. However, an opportunity now exists for emerging transdisciplinary scholars to think carefully about the methodological development and practice of transdisciplinarity in order to avoid what I have described in this paper as another wave of colonisation for the world's indigenous peoples. In particular, the use of transdisciplinarity in cross-cultural endeavor is a skill that must be learnt - the same as any research method
- and ideally should be combined with the development of competency in the language of those socalled 'non-scientific' communities that participate in cross or trans-cultural research endeavours. There is also an urgent need for transdisciplinary scholars to engage in emerging decolonising literatures.

Finally, I have noted in this chapter that in order to survive, the members of a cultural group require the freedom to give daily expression to their distinctive language, values and cultural institutions within functioning cultural ecosystems, landscapes and nation states. Culturally-mediated efforts to create knowledge as a basis for survival requires recognition, encouragement and financial support from world governments and corporate entities. If, as a global community we are unable to provide conditions and support of this kind, if we are unable to recognise the past, present and future value of culture, then over the next 100 years we currently stand to loose somewhere between $50-90 \%$ of our current linguistic and cultural diversity [12]. Thus, given the findings of this chapter, it seems appropriate to make a plea that we can please make room for an indigenous transdiscplinarity in the western academy.

Funding: This research received no external funding.

Conflicts of Interest: The author declare no conflict of interest.

\section{References}

[1] Smith, L. T. (1999). Decolonising methodologies research and indigenous peoples. London: ProQuest.

[2] Patel, L. (2016). Decolonising educational research: from ownership to answerability. New York, NY: Routledge.

[3] Denzin, N. K. and Giardina, M. D. (eds.). (2007). Ethical futures in qualitative research: decolonising the politics of knowledge. (279 p.). Walnut Creek, CA: Left Coast Press

[4] Apffel-Marglin, F. and Marglin, S. A. (eds.). (1996). Decolonising knowledge: from development to dialogue. Studies in development economics. (vi, 398 p.). New York, NY: Clarendon Press

[5] Harrison, F. V. (ed.). (1997). Decolonising anthropology: moving further toward an anthropology of liberation. (2nd ed.). (xi, 200 p.). Arlington, VA: Association of Black Anthropologists, American Anthropological Association. 
[6] Wilson, A. C. and Yellow Bird, M. (2005). For indigenous eyes only: a decolonization handbook. Decolonization handbook. Santa Fe: School of American Research.

[7] Najita, S. Y. (2006). Decolonising cultures in the Pacific: reading history and trauma in contemporary fiction. (xviii, 236 p.). Routledge research in postcolonial literatures 14. New York, NY: Routledge.

[8] Max-Neef, M. A. (2005). Foundations of transdisciplinarity. Ecological Economics, 53(1), 5-16.

[9] Nicolescu, B. (2005). Transdisciplinarity, Past, Present and Future. Paper Presented at the 2nd World Congress on Transdisciplinarity. Vitoria, Vela Velha, Brazil. 6-12 September 2005.

[10] McGregor, S. L. T. (2015). The Nicolescuian and Zurich Approaches to Transdisciplinarity. Integral Leadership Review (April-June), 6-16.

[11] Nicolescu, B. (2008). Transdisciplinarity: theory and practice. (320 p.). Cresskill, USA: Hampton Press.

[12] Romaine, S. (2015). The Global Extinction of Languages and Its Consequences for Cultural Diversity. In Marten, H. F., Rieler M., Saarikivi, J. Toivanen R. (eds.). Cultural and linguistic minorities in the Russian Federation and the European Union: comparative studies on equality and diversity. (31-46 pp.). New York, NY: Springer.

[13] McGuinness, W. and White, M. (2011). Nation dates. Wellington, NZ: Pivotal Press.

[14] Kepa, M. (2008). Languages and cultures: Learning and teaching betwixt worlds. Alter Native: an International Journal of Indigenous Peoples 4(1), 57-66.

[15] Morehu, C. (2009). Language re-vitalisation and cultural transformation. Mai Review (1), 1-12.

[16] Arabski, J. and Wojtaszek, A. (2011). Aspects of culture in second language acquisition and foreign language learning. Second language learning and teaching. New York, NY: Springer.

[17] Jeurissen, M. (2014). Te Reo Māori as a subject: The impact of language ideology, language practice, and language management on secondary school students' decision making. Australian Journal of Indigenous Education, 43(2), 175-184.

[18] McLellan, K.M., McCann, C. M., Worrall, L. E. and Harwood, M. L. N. (2014). For Māori language is precious. And without it we are a bit lost: Māari experiences of aphasia. Aphasiology, 28(4), 453-470.

[19] Bishop, R., (2003). Changing power relations in education: Kaupapa Māori messages for 'mainstream' education in Aotearoa New Zealand. Comparative Education, 39(2), 221-238.
[20] Bishop, R., Berryman, M., Cavanagh, T. and Teddy, L. (2009). Te Kotahitanga: Addressing educational disparities facing Māori students in New Zealand. Teaching and Teacher Education, 25(5), 734-742.

[21] Bishop, R., (2012). Pretty difficult: Implementing kaupapa Māori theory in English-medium secondary schools. New Zealand Journal of Educational Studies, $47(2), 38-50$.

[22] Smith, L. T. (2012). Decolonising methodologies: research and indigenous peoples. (2nd ed.). (xv, 240 p.). Dunedin, NZ: Otago University Press.

[23] Freire, P., (1993). Pedagogy of the oppressed. London, England: Penguin Books.

[24] Smith, G.H., (1999). Paulo Freire: Lessons in transformative praxis, in Paulo Freire, politics and pedagogy. Reflections from Aoteaora. (35-42 pp.). Palmerston North, NZ: Dunmore Press.

[25] Jenkins, K. and Martin, B. (1999). Tidal waves of change: divine work with Paulo Freire, in Paulo Freire, politics and pedagogy. Reflections from Aoteaora. (43-60 pp.). Palmerston North, NZ: Dunmore Press.

[26] Armstrong, G. A. W. (1999). After 25 years: Paulo Freire in New Zealand, 1974, in Paulo Freire, politics and pedagogy. Reflections from Aoteaora. p. (23-34 pp.). Palmerston North, NZ: Dunmore Press.

[27] Shilenge, Z. (2016). Using Transdisciplinarity of Indigenous Knowledge Systems in Food Security Research. Journal of Social Sciences, 46(2), 155-164.

[28] Nabudere, D. W. (2012). Afrikology and transdisciplinarity a restorative epistemology. Pretoria, SA: Africa Institute of South Africa.

[29] Haavelsrud, M. (2015). The academy, development, and modernity's 'other'. International journal of development education and global learning, 7(2), 4660.

[30] Chilisa, B. (2017). Decolonising transdisciplinary research approaches: an African perspective for enhancing knowledge integration in sustainability science. Sustainability Science, 12(5), 813-827.

[31] Newbigin, L. (1995). Proper confidence: faith, doubt, and certainty in Christian discipleship. Grand Rapids, Mich: Eerdmans.

[32] Sire, J. W. (2010). The universe next door; a basic worldview catalog. (5th ed.). Portland, USA: Ringgold Inc.

[33] Lozowski, P. (2013). The linguistic worldview: ethnolinguistics, cognition, and culture, In Gaz, A., Danaher, D. and Lozowski, P. (ed.). London, England: Versita, Versita Limited.

[34] Sire, J. W. (2015). Naming the elephant: worldview as a concept. (2nd ed.). Downers Grove, Illinois: InterVarsity Press. 
[35] Underhill, J. W. (2009). Humboldt, worldview and language, In Underhill, J. W. (ed.). Edinburgh, UK: Edinburgh University Press.

[36] Ngata, H. M., Ngata, W., Ngata, H. M. and Learning Media (1990). Ngata Dictionary. Wellington, NZ: Learning Media.

[37] Ngata, H. M., Ministry of Education and Learning Media. (1993). English-Maori dictionary, In Ngata, W. (ed.). Wellington, NZ: Learning Media.

[38] Cheung, M. (2008). The reductionist-holistic worldview dilemma. Mai Review, (3), 1-7.

[39] Marsden, M., (2003). Kaitiakitanga: a definitive introduction to the holistic worldview of the Māori. In Royal T. A. C. (ed.). The woven universe: selected writings of Rev. Māori Marsden. (54-72 pp.). Ōtaki, NZ: Estate of Rev. Māori Marsden.

[40] Smith, G., Hoskins, T. K. and Jones, A. (2012). Interview: Kaupapa Māori: The dangers of domestication. New Zealand Journal of Educational Studies, 47(2), 10-20.

[41] Keegan, P. J. (2012). Making sense of kaupapa Māori: A linguistic point of view. New Zealand Journal of Educational Studies, 47(2), 74-84.

[42] Cooper, G. (2012). Kaupapa Māori research: Epistemic wilderness as freedom? New Zealand Journal of Educational Studies, 47(2), 64-73.

[43] Black, J., (2004). The literature of ancient Sumer, In Black. J. A. (ed.). Oxford, UK: Oxford University Press.

[44] Leverington, D. (2013). Babylonian Astronomy. United Kingdom, Cambridge University Press.

[45] Bahrani, Z. (2003). The graven image representation in Babylonia and Assyria. Philadelphia, USA: University of Pennsylvania Press.

[46] Charpin, D. (2010). Writing, law, and kingship in Old Babylonian Mesopotamia. In Todd. J. M. (ed.). Chicago, USA: University of Chicago Press.

[47] Friberg, J. (2005). Unexpected links between Egyptian and Babylonian mathematics. Hackensack, NJ: World Scientific.

[48] Friberg, J. (2007). Amazing traces of a Babylonian origin in Greek mathematics. London, UK: World Scientific.

[49] Curits, J. and Tallis, N. (2005). Forgotten empires: the worlds of ancient Persia. California, USA: University of California Press.

[50] Bloomer, W. M. (2015). A companion to ancient education. London, UK: Wiley-Blackwell.

[51] Dusenbury, D. L. (2017). Platonic legislations: an essay on legal critique in ancient Greece. Switzerland: Springer.
[52] Gagarin, M. (2013). Laws and Legislation in ancient Greece. (219-234 pp.). Oxford, UK: Blackwell Publishing Ltd.

[53] Hannah, R. (2015). The roles of observational astronomy in ancient Greece. Scientific Culture, 1(2), 47-56.

[54] Landels, J. G. (1999). Music in ancient Greece and Rome. London, UK: Routledge.

[55] Markus, A. (2013). Writing science: medical and mathematical authorship in ancient Greece. Asper M. (ed.). Berlin, De: Gruyter.

[56] Neils, J. (2013). Picturing victory, representations of sport in Greek art. (81-97 pp.). Oxford, UK: John Wiley Sons.

[57] Patricia, F. O. (2005). Meet the philosophers of ancient Greece. London, UK: Ashgate Publishing.

[58] Raaflaub, K. A. (2007). Origins of democracy in ancient Greece. Ober J. and Wallace, R. W. (ed.). Berkeley, CA: University of California Press.

[59] Robb, K. (1994). Literacy and paideia in ancient Greece. New York, NY: Oxford University Press.

[60] Sage, M. M. (1996). Warfare in ancient Greece: a sourcebook. London, UK: Routledge.

[61] Walden, J. W. H. (1970). The universities of ancient Greece. Freeport, N.Y: Books for Libraries Press.

[62] Anderson, J. C. (2013). Architect and patron. (127139 pp.). Oxford, UK: Blackwell Publishing Ltd.

[63] Birley, A. (2000). Marcus Aurelius, a biography. (2nd ed.). London, UK: Routledge.

[64] Bliquez, L. J. (2015). The tools of Asclepius, surgical instruments in Greek and Roman times. Netherlands: Brill.

[65] Duncan-Jones, R. (1974). The economy of the Roman empire: quantitative studies. Cambridge, UK: University Press.

[66] Grant, M. (1995). Art in the Roman Empire. London, UK: Routledge.

[67] Israelowich, I. (2015). Patients and healers in the High Roman Empire. Baltimore, DC: Johns Hopkins University Press.

[68] Kemezis, A. (2015). Urban dreams and realities in antiquity, remains and representations of the ancient city. Kemezis, A. M. (ed.). Netherlands: Brill.

[69] Too, Y. L. (2001). Education in Greek and Roman antiquity. Too, Y. L. (ed.). Netherlands: Brill.

[70] Levick, B. (2000). The government of the Roman Empire: a sourcebook. (2nd ed.). Levick. B. (ed.). London, UK: Routledge.

[71] Magnusson, R. J. (2001). Water technology in the Middle Ages cities, monasteries, and waterworks 
after the Roman Empire. Baltimore, DC: Johns Hopkins University Press.

[72] Millar, F. (2004). Government, society, and culture in the Roman Empire. Cotton H. and Rogers, G. M. (ed.). London, UK: Eurospan.

[73] Mousourakis, G. (2012). Fundamentals of Roman private law. Heidelberg, De: Springer.

[74] Bennison, A. K. (2009). The great caliphs the golden age of the Abbasid Empire. New Haven, Co: Yale University Press.

[75] El-Ashker, A. A. (2006). Islamic economics a short history. Wilson, R. (ed.). Netherlands: Brill.

[76] Freely, J. (2011). Light from the east: how the science of medieval Islam helped to shape the western world. New York, NY: I. B. Tauris.

[77] Lombard, M. (2003). The golden age of Islam. Princeton, NJ: Markus Wiener Publishers.

[78] Merzbach, U. C. (2011). A history of mathematics. (3rd ed.). Boyer, C. B. (ed.). Hoboken, NJ: John Wiley.

[79] Tiliouine, H. (2016). The state of social progress of Islamic societies: social, economic, political, and ideological challenges, (ed.). Tiliouine, H. and Estes, R. J. Switzerland: Springer.

[80] Waitangi Tribunal. (1989). Report of the Waitangi tribunal on the Te Reo Māori claim. Wellington, NZ: Government Printer.

[81] Demerath, L. (2002). Epistemological culture theory: a micro theory of the origin and maintenance of culture. Sociological Theory, 20(2), 208-226.

[82] Gibbons, M. Limoges, C. Nowotny, H. Schwartzman, S. Scott, P. and Trow, M. (1994). The new production of knowledge: the dynamics of science and research in contemporary societies. London, UK: SAGE Publications.

[83] MORST. (2007). Vision mātauranga: unlocking the innovation potential of Māori knowledge, resources and people. (24 p.). Wellington, NZ: Ministry for Research, Science and Technology.

[84] Klein, J. T. (2001). Transdisciplinarity, joint problem solving among science, technology, and society: an effective way for managing complexity. (xiii, 332 p.). Synthesebücher, Basel: Birkhäuser.

[85] Comenius, J. A. (1998). The labyrinth of the world and the paradise of the heart. New York, NY: Paulist Press.

[86] Comenius, J. A. (1969). A reformation of schooles, 1642. Menston, Yorks: Scolar P.

[87] Comenius, J. A. (1957). John Amos Comenius, 15921670, selections. Paris: Unesco.
[88] Beneš, E. (1942). The teacher of nations. Addresses and essays in commemoration of the visit to England of the great Czech educationalist Jan Amos Komenský, Comenius, 1641-1941. Needham, J. (ed.). Cambridge, UK: Cambridge University Press.

[89] Funtowicz, S. O. and Ravetz, J. R. (1993). Science for the post-normal age. Futures, 25(7), 739-755.

[90] Gibbons, M. (2000). Appendix: Some attributes of knowledge production in mode 2. Kraak, A. (ed.). (113-140 pp.). South Africa: HSRC Press.

[91] Gibbons, M. (2000). Universities and the new production of knowledge: some policy implications for government. Kraak, A. (ed.). (34-44 pp.). South Africa: HSRC Press.

[92] Linder, F. and Spear, J. (2003). Re-thinking science: knowledge and the public in an age of uncertainty. Contemporary Sociology, 32(2), 255-257.

[93] Smith, L. T. Maxwell, T. K. Puke, H. and Temara, P. (2016). Feature article: indigenous knowledge, methodology and Mayhem: what is the role of methodology in producing indigenous insights? A discussion from Mātauranga Māori. Knowledge Cultures, 4(3), 131-156.

[94] Durie, M. (2010). Outstanding universal value: how relevant is indigeneity?, In Selby, R. Moore, P. and Mulholland, M. (ed.). Māori and the environment: kaitiaki. (239-250 pp.). Wellington, NZ: Huia.

[95] Rodríguez, R. C. (2014). Our sacred maiz is our mother: indigeneity and belonging in the Americas. Hernández, V. C. (ed.). Tucson, Ar: The University of Arizona Press.

[96] Maaka, R. (2005). The politics of indigeneity: challenging the state in Canada and Aotearoa New Zealand. Fleras. A. (ed.). Dunedin, NZ: University of Otago Press.

[97] Forte, M. C. (2010). Indigenous cosmopolitans: transnational and transcultural indigeneity in the twenty-first century. New York, NY: Peter Lang.

[98] Fatima, P. L. Shauneen, P. and Fran, M. (2017). Culturally responsive pedagogy: working towards decolonisation, indigeneity and interculturalism. Cham: Springer.

[99] Devine Guzmán, T. (2013). Native and national in Brazil: indigeneity after independence. Chapel Hill, NC: The University of North Carolina Press.

[100] Harris, L. D. and Wasilewski, J. (2004) Indigeneity, an alternative worldview: Four R's (Relationship, Responsibility, Reciprocity, Redistribution) vs. two P's (power and profit). Sharing the journey towards conscious evolution. Systems Research and Behavioral Science, 21(5), 489-503. 
[101] Smith, G. Hoskins, T. K. and Jones, A. (2012). Interview Kaupapa Māori: The dangers of domestication. New Zealand Journal of Educational Studies, $47(2), 10-20$.

[102] Walker, S. Eketone, A. and Gibbs, A. (2006). An exploration of kaupapa Māori research, its principles, processes and applications. International Journal of Social Research Methodology, 9(4), 331-344.

[103] Marsden, M. (2003). The woven universe: selected writings of Rev. Māori Marsden. Royal. C. (ed.). (xxxviii, 187 p.). Ōtaki, NZ: Estate of Rev. Māori Marsden.

[104] Taylor, J. C. (2001). The Quantum Revolution. (214259 pp.). Cambridge, UK: Cambridge University Press.

[105] Jones, S. (2008). The quantum ten a story of passion, tragedy, ambition and science. Oxford, UK: Oxford University Press.

[106] Heelan, P. A. (2016). The observable: Heisenberg's philosophy of quantum mechanics. Bitbol, M. and Babich, B. (ed.). New York, NY: Peter Lang.

[107] Simon, J. A. Smith L. T. and Cram F. (2001). A civilising mission?: perceptions and representations of the Native Schools system. (xiv, 357 p.). Auckland, NZ: Auckland University Press.

[108] Ratima, M. (2008). Making space for Kaupapa Māori within the academy. Mai Review, (1), 1-3.

[109] Binney, J. (1987). Māori Oral Narratives, Pākehā Written Texts - 2 Forms of Telling History. New Zealand Journal of History, 21(1), 16-28.

[110] Wehi, P. M. Whaanga, H. and Roa, T. (2009). Missing in translation: Māori language and oral tradition in scientific analyses of traditional ecological knowledge (TEK), Journal of the Royal Society of New Zealand, 39(4), 201-204.

[111] Galilei, G. (1953). Dialogue concerning the two chief world systems, Ptolemaic 83 Copernican. (xxvii, 496 p.). Berkeley, Ca: University of California Press.

[112] Nicolescu, B. (1985) Nous, la particule et le monde. Le Rocher, Monaco, Transdisciplinarity Series, 2002. (2nd ed.). Paris: Le Mail.
Anthony Cole: Tainui is my canoe. Tararua is my mountain. Ōtaki is my river. Ngāti koroki is my hapū (transl. extended family). Ngāti Raukawa ki te Tonga is my iwi (transl. an extended kin group). Anthony is my name and I am a descendent of the Māori peoples who travelled the South Pacific ocean in canoes and settled in Aotearoa (transl. New Zealand) approximately 1000 years ago. While I was trained in the western academy, I work primarily in a Māori community context with a focus on Māori cultural survival and wellbeing.

\section{About the Author}

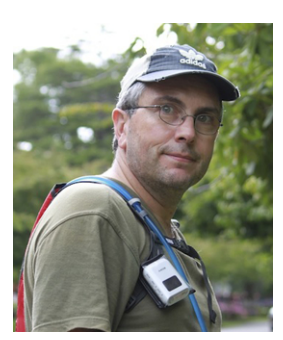

